\title{
An unexpected fungal infection in a patient with leukaemia
}

\author{
BERYL JAMESON, RL CARTER, JG WATSON, AND RJ HAY* \\ From the Royal Marsden Hospital, Sutton, Surrey, and *The London School of Hygiene and Tropical \\ Medicine, UK
}

SUMMARY A 58-year-old man, who was entering remission from acute monocytic leukaemia, died unexpectedly after five days of fever. Cultures of necropsy material grew the yeast Trichosporon beigelii, and subsequent histological examination showed a widely disseminated infection. This fungus usually causes a localised lesion of the hair shaft (piedra). Deep-seated infections due to Trichosporon spp. have been recorded infrequently and disseminated infections on only five previous occasions. None of these has been from the United Kingdom. This case report describes some of the difficulties of diagnosis.

A 58-year-old chartered engineer was well until he presented with a two-month history of indigestion and a loss of $5 \mathrm{~kg}$ in weight. He had had seven days' cough with clear sputum, night sweats, and left pleuritic chest pain.

Examination showed a small faucial ulcer, a onefingerbreadth palpable liver, and a small fundal haemorrhage. A blood count revealed haemoglobin $8.1 \mathrm{~g} / \mathrm{dl}$, white cells $10 \times 10^{\%} / 1$, and platelets $68 \times 10^{9} / 1$. The bone marrow contained $60 \%$ monocytoid blasts, and a diagnosis of acute monocytic leukaemia $\left(\mathbf{M}_{5}\right)$ was made.

He was treated with seven days' 6-thioguanine, five days' cytosine arabinoside, two days' Rubidazone, and seven days' prednisolone. During this time he was nursed in protective isolation and given oral co-trimoxazole, nystatin, and amphotericin B as antimicrobial prophylaxis. Fourteen days later the bone marrow contained $6 \%$ blasts, and the chemotherapy course was repeated.

Two days after this ended he complained of generalised aches, optic myalgia, and faintness. Fever of $39 \cdot 2^{\circ} \mathrm{C}$ was treated empirically with gentamicin and ticarcillin. During the next four days he remained pyrexial, developed right-sided pleurisy and a pericardial rub, and became jaundiced. Bacterial, fungal, and viral cultures were uninformative. Chest $x$-rays were normal.

Next morning he was in mild cardiac failure, and the liver was palpable at three finger-breadths. On that day he died.
POSTMORTEM EXAMINATION

A necropsy was performed 48 hours after death. Both lungs appeared congested and haemorrhagic with small scattered zones of consolidation; the pleural sacs were dry. The heart showed a few epicardial haemorrhages, and the myocardium was pale. There was no evidence of pericarditis.

The stomach contained several shallow erosions. The liver was pale and soft and contained firm, white foci, up to $0.5 \mathrm{~cm}$ in diameter, scattered throughout its substance. Similar nodules were found in the spleen, which was slightly enlarged. Both kidneys had focal haemorrhage in the renal pelves. Spinal and femoral bone marrow were pale.

\section{Histology}

Histological examination showed that the white focal lesions in the spleen and liver were mycotic abscesses. Similar microscopic lesions were found in smaller numbers in both lungs, the myocardium, and both kidneys. The abscesses consisted of dense masses of 'hyphae' and yeasts surrounded by necrotic tissue debris (Fig. 1). The 'hyphae' were characteristically broad, measuring $8-10 \mu$ in diameter, and in some regions showed a banded appearance due to the presence of arthrospores (Fig. 2). Demonstration of fungal elements by periodic-acidSchiff (PAS) and Grocott's methenamine silver stains proved to be difficult, and prolonged staining was necessary. Inflammatory cells were absent, and 
Fig. 1 Mycotic abscesses in spleen stained by periodic-acid-Schiff: $\times 220$.

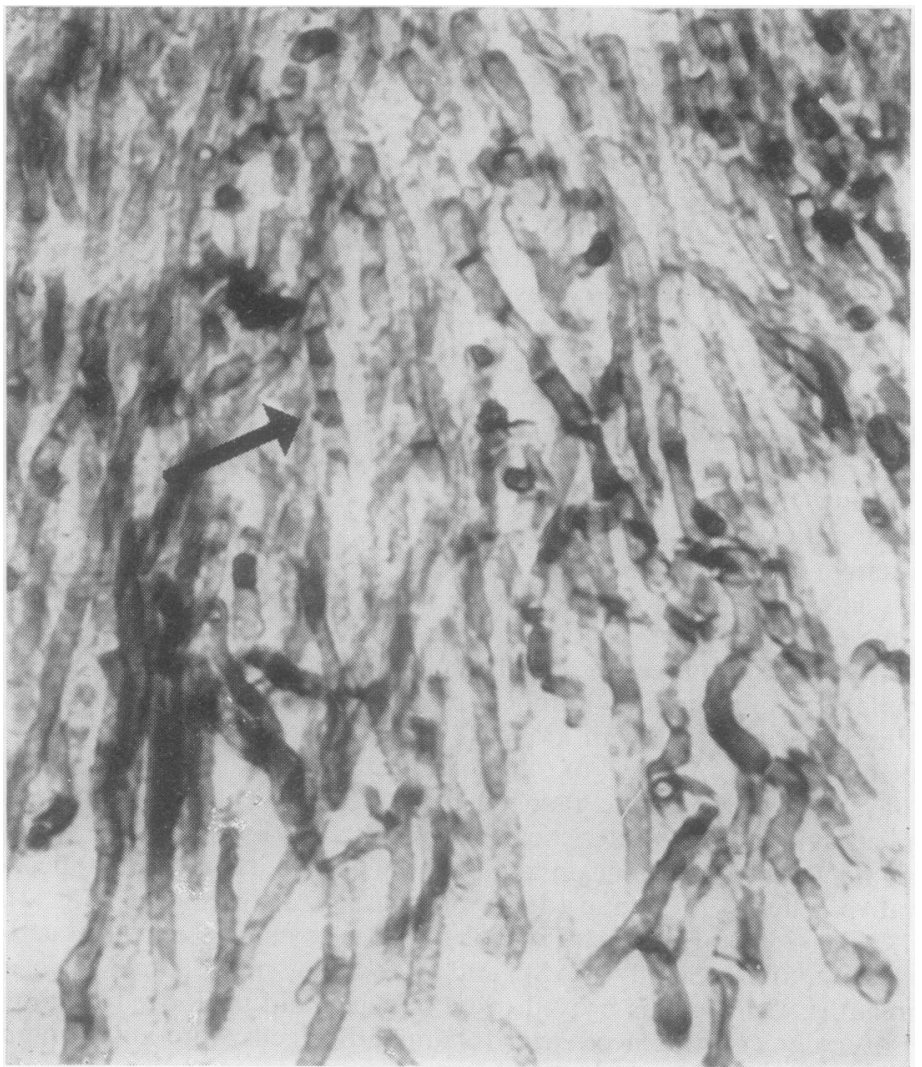

Fig. 2 Characteristic arthrospores indicated by arrow. $\times 840$. 
the abscesses were not encapsulated. No evidence of residual leukaemia was found.

\section{Necropsy microbiology}

After overnight incubation on blood agar at $37^{\circ} \mathrm{C}$, cultures of lung and pericardium grew rough, yellow-grey colonies resembling those of Bacillus spp. On Sabouraud's medium, at room temperature and at $37^{\circ} \mathrm{C}$, equally rapid growth resulted in discrete, heaped-up, cream-coloured colonies. Gramstained films showed both pear-shaped yeasts and distinctive chains of arthrospores (Fig. 3). The organism was later identified as Trichosporon beigelii. Geotrichum spp. were excluded by the presence of blastospores, and the isolate was distinguished from $T$. capitatum by the production of urease and the pattern of carbohydrate assimilation.

The fungus was grown after three weeks' incubation from a blood culture taken on the day before death.

\section{Serology}

The patient's stored antemortem serum was examined for fungal antibodies. There was no evidence, using either immunofluorescence (IF) or counterimmunoelectrophoresis, of antibodies to candida or Aspergillus species. With IF, however, using $T$. beigelii blastospores air-dried on to glass slides, the patient's serum showed an antibody titre of $1: 8$. Control sera were all negative, and the reaction could be blocked by absorption with $T$. beigelii cells.
The organism was demonstrated in liver tissue by indirect immunofluorescence. ${ }^{1}$

\section{Discussion}

Disseminated infections with $T$. beigelii and the closely related $T$. capitatum are rare. Five have been reported: three due to $T$. beigelii (cutaneum), ${ }^{2}{ }^{3}$ one to $T$. capitatum, ${ }^{4}$ and one to Trichosporon $\mathrm{sp}^{5}$ All were in severely immunosuppressed hosts.

Focal, deep-seated infections are infrequent. Pulmonary infections have been recorded: 67 two patients with endophthalmitis have been described ${ }^{8}$ and one instance each of endocarditis, ${ }^{9}$ brain abscess, ${ }^{10}$ and peritonitis during dialysis. ${ }^{11}$

$T$. beigelii is associated with a superficial infection of hair (white piedra), while $T$. capitatum is not usually recognised as a pathogen. Both are widely distributed in the soil and other parts of the environment ${ }^{12}$ as well as being recognised as constituents of the normal human microbial flora. ${ }^{13}$ They have been isolated from sputum, and it is suggested that inhalation is the route of entry to infected patients.

The unusually rapid (overnight) growth of this fungus on culture media should make recognition easy, and its presence in a diagnostic specimen ought to alert the clinician to the possibility of its being a pathogen in an immune-suppressed patient. In tissue section, it should be noted that staining of the fungus is difficult. In the case described here it was

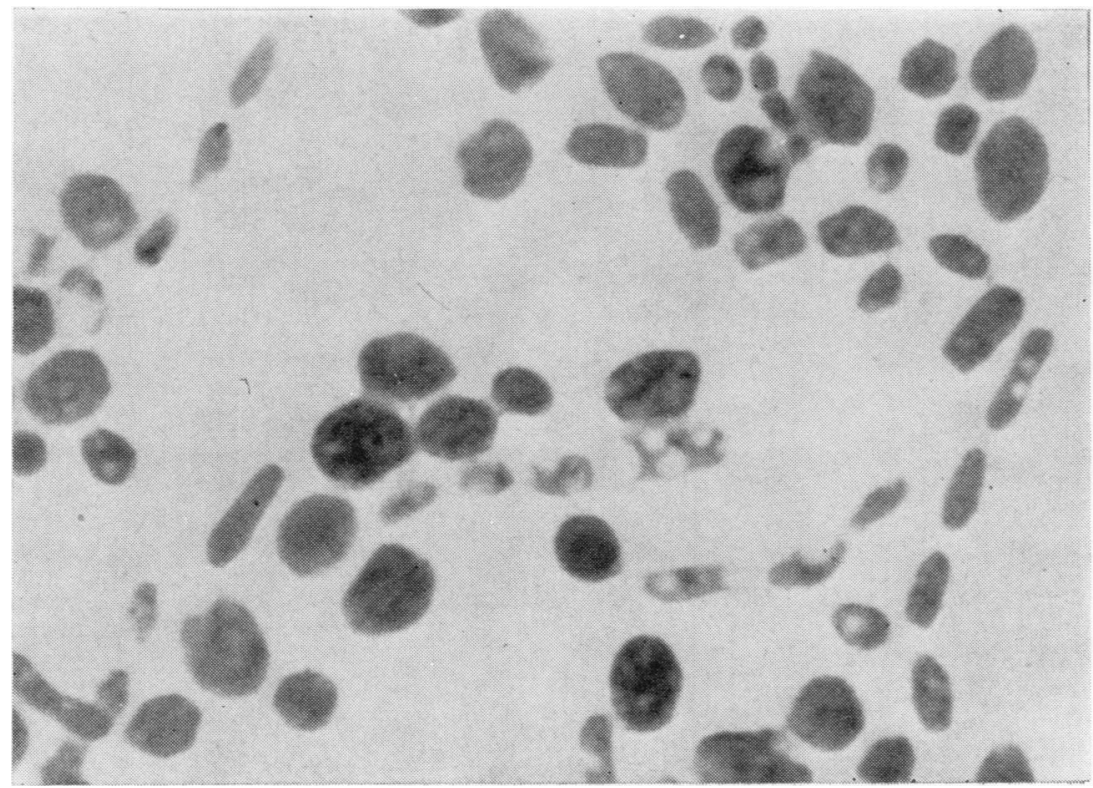

Fig. 3 Gram-stained film of overnight culture showing pear-shaped forms and arthrospores. $\times 1200$. 
necessary to extend exposure to periodic acid in the PAS stain from the normal time of 8 to 30 minutes; and in the Grocott methenamine silver method, instead of the normal 45-60 minutes, up to 2 hours was required.

So far, disseminated infections have been recognised only at necropsy, but increasing awareness of trichosporon as a lethal pathogen should lead to a more vigorous search, for example in the paranasal sinuses, as suggested by Winston et al. ${ }^{4}$

Amphotericin B, possibly in combination with 5-fluorocytosine, might be successful treatment, ${ }^{49}$ but in our patient it seems unlikely that treatment would have been successful because the short duration and non-specific nature of the symptoms would not have indicated the use of empirical antifungal therapy.

We thank the Mycology Laboratory of the Brompton Hospital for primary identification of the fungus, and the Mycological Reference Laboratory, The London School of Hygiene and Tropical Medicine, for serology and immunofluorescence. We are grateful to Dr RL Powles for permission to publish this case report.

\section{References}

${ }^{1}$ Kaplan W, Kraft DE. Demonstration of pathogenic fungi in formalin-fixed tissues by immunofluorescence. $A m J$ Clin Pathol 1969;52:420-37.
${ }^{2}$ Rivera R, Cangir A. Trichosporon sepsis and leukaemia. Cancer 1975;36:1106-10.

"Evans HL, Kletzel M, Lawson RD, Frankel LS, Hopfer RL. Systemic mycosis due to Trichosporon cutaneum. Cancer 1980;45:367-71.

+ Winston DJ, Balsley GE, Rhodes J, Linné SR. Disseminated Trichosporon capitatum infection in an immunosuppressed host. Arch Intern Med 1977;137:1192-5.

${ }^{5}$ Kirmani N, Tuazon CU, Geelhoed GW. Disseminated Trichosporon infection. Occurrence in an immunosuppressed patient with chronic active hepatitis. Arch Intern Med 1980;140:277-8.

${ }^{6}$ Gemeinhardt H. Lungenpathogenität von Trichosporon capitatum beim Menschen. Zentralbl Bakteriol (Orig A) 1965;196:121-33.

' Fonseca OD. Deep skin and pulmonary mycosis in Brazil. In: Therapy of Fungal Diseases. London: Churchill. 1956.

${ }^{8}$ Sheikh HA, Mahgoub S, Badi K. Postoperative endophthalmitis due to Trichosporon cutaneum. Br J Ophthalmol 1974;58:591-4.

9 Marier R, Zakhireh B, Downs J, Wynne B, Hammond GL, Andriole VT. Trichosporon cutaneum endocarditis. Scand J Infect Dis 1978;10:255-6.

${ }^{10}$ Watson $\mathrm{KC}$, Kallichurum S. Brain abscess due to Trichosporon cutaneum. J Med Microbiol 1970;3:191-3.

${ }^{11}$ Khauna R, Oreopoulos DG, Vas S, McNeely D, McCready W. Treating fungal infections (letter). $B r$ Med J 1980;2: 1147.

12 Lodder J. The Yeasts. 2nd edn. Amsterdam: North Holland Publishing Co, 1971.

${ }^{13}$ Ahearn DG. Medically important yeasts. Ann $R e^{\prime}$. Microbiol 1978;32:59-68.

Requests for reprints to: Dr Beryl Jameson, The Royal Marsden Hospital, Downs Road, Sutton, Surrey SM2 5PT. 